\title{
Ionic Liquid Based Vilsmeier Reagent as an Efficient Reagent for Esterification of Alcohols and Carboxylic Acids
}

\author{
Ahmed Ali Hullio' ${ }^{*}$, G. M. Mastoi ${ }^{2}$, Hassan Imran $^{3}$ \\ ${ }^{1}$ Dr. M.A Kazi Institute of Chemistry, University of Sindh, Jamshoro, Pakistan \\ ${ }^{2}$ Institute of Advanced Research Studies in Chemical Sciences, University of Sindh, Jamshoro, Pakistan \\ ${ }^{3}$ National Centre of Excellence for Analytical Chemistry, University of Sindh, Jamshoro, Pakistan \\ Email: *ahmedalihullio@yahoo.com
}

How to cite this paper: Hullio, A.A., Mastoi, G.M. and Imran, H. (2018) Ionic Liquid Based Vilsmeier Reagent as an Efficient Reagent for Esterification of Alcohols and Carboxylic Acids. International Journal of Organic Chemistry, 8, 125-134.

https://doi.org/10.4236/ijoc.2018.81008

Received: October 27, 2017

Accepted: March 6, 2018

Published: March 9, 2018

Copyright $\odot 2018$ by authors and Scientific Research Publishing Inc. This work is licensed under the Creative Commons Attribution International License (CC BY 4.0).

http://creativecommons.org/licenses/by/4.0/

\begin{abstract}
The Vilsmeier reagent is well-known electrophilic reagent for synthetically useful organic transformations. Its ionic liquid version has been prepared from DMF-like ionic liquid. Apart from its other reported applications, presently it has been used as an efficient organo reagent for efficient esterification. Variety of esters has been prepared from versatile carboxylic acids and alcohols under ionic liquid conditions with excellent yields. The present system offers an economically and environmentally better alternative to routine procedures.
\end{abstract}

\section{Keywords}

Dehydration Agent, Ionic Liquid Based Vilsmeier Reagent, Esterification

\section{Introduction}

One of the main objects of current research pursuits has been to find efficient and economical methodologies for synthetically useful transformations. More recently, a new dimension has been added to improved organocatalysis i.e. to make the procedures green and environmentally benign. Many synthetically useful organic reactions have been achieved by using organic molecules as catalysts. However the organocatalysed reactions suffer immensely from their inherent draw backs like toxicity, high cost, laborious procedure and hectic work up to obtain pure products. An idea of converting organocatalysts into their ionic liquid versions has revolutionized the field of organocatalysis. This is achieved by attaching an organocatalyst with cationic part of an ionic liquid and resulting 
reagent is called functional ionic liquid or task specific ionic liquid. This leads to improved catalytic efficiency, minimal toxicity, easy procedure and recycling of the catalyst. Various types of task specific ionic liquids have been used to achieve key chemical transformations [1].

$N, N$-Dimethylchlorosulfitemethaniminium chloride ( $\left.\mathrm{SOCl}_{2}-\mathrm{DMF}\right)$, known as Vilsmeier reagent is well known powerful electrophilic reagent to achieve some synthetically useful reactions [2]. The Vilsmeier reagent is usually prepared by treating the dimethylformamide (DMF) with an appropriate chlorinating agent like thionylchloride, oxylyl chloride, phosphorus pentachloride or cyanuric chloride. The scope of its application is wide as evident from reporting of large number of reviews about its applications.

The Vilsmeier reagent has been used to achieve key synthetic transformations such as direct $N$-alkylation of phthalimide by alcohols as alkylating agents [3] conversion of different alcohols to the corresponding alkyl chlorides [4], tetrahydropyranylation of primary, secondary and tertiary alcohols and phenols [5] [6] conversion of ketoximes into the corresponding amides and aldoximes to nitriles [7], Lossen rearrangement of hydroxamic acids to form isocyanates [8]. However high water sensitivity renders this reagent quite difficult to handle and extra care is observed during its preparation and application. In order to overcome this drawback, we reported its ionic liquid version which is hydrophobic and thus easy to handle. And we have successfully performed above said reactions with ionic liquid version of Vilsmeier reagent with improved efficiency and ease [9].

Due to its oxophilic nature, Vilsmeier reagent demonstrates the tremendous tendency to react with nucleophillic oxygen like hydroxy group thereby promoting many useful reactions. Apart from other applications, it has also been used for the activation of carboxyl group in various synthetic transformations. Esterification reaction of alcohols and carboxylic acids is an important transformation in organic synthesis and a variety of methods has been developed to accomplish it [10]. The Vilsmeier reagent has also been shown to have the potential to cause the esterification between structurally diverse carboxylic acids and alcohols. Kaula et al. reported its use as an efficient reagent for one-pot synthesis of esters from equimolar amounts of fatty acids and hindered alcohols under mild conditions [11].

In continuation of our ongoing projects on exploration of applications of DMF-like ionic liquid to justify its "multipurpose" nature, presently we have examined its potential as a dehydrating agent for reactions involving dehydrative eliminations.

\section{General Methods and Procedures}

\subsection{Material}

All chemical were purchased from Aldrich. All reagents and solvents were used without further purification. Buchi 510 melting point apparatus was employed 
to determine the melting points of products. IR spectra were run on a Shimadzu FT-IR 8300 spectrophotometer. ${ }^{1} \mathrm{H}$ NMR and ${ }^{13} \mathrm{C}$ NMR spectra were recorded in $\mathrm{CDCl}_{3}$ and DMSO- $\mathrm{d}_{6}$ using a Bruker Avance DPX instrument $\left({ }^{1} \mathrm{H}\right.$ NMR 400 $\mathrm{MHz},{ }^{13} \mathrm{C}$ NMR $300 \mathrm{MHz}$ ). The mass spectra were recorded on a Shimadzu GC-MS QP 1000 EX instrument. Elemental analyses were run on a Thermo Finnigan Flash EA-1112 series.

\subsection{Parameters for GC-MS}

Agilent 6890 N Network System equipped with capillary column HP-5MS (30 m $\times 0.25 \mathrm{~mm}$ i.d., $0.25 \mu \mathrm{m}$ film thickness). The electron ionization (EI) mode at 70 $\mathrm{eV}$ was used for MS detection. The temperature of oven was held at $90^{\circ} \mathrm{C}$ for 1 min, raised to $200^{\circ} \mathrm{C}$ at $5^{\circ} \mathrm{C} / \mathrm{min}$ ( $2 \mathrm{~min}$ hold) and then to $280^{\circ} \mathrm{C}$ at $20^{\circ} \mathrm{C} / \mathrm{min}$ (12 min hold). $1 \mu \mathrm{L}$ sample was injected in hexane (HPLC grade), using splitless mode. The carrier gas Helium was used at a flow rate of $1.5 \mathrm{~mL} / \mathrm{min}$. The injector and MS transfer line temperature was set at $220^{\circ} \mathrm{C}$ and $290^{\circ} \mathrm{C}$, respectively.

\subsection{General Procedure for Ionic Liquid-Based Vilsmeier Reagent Catalysed Esterification}

For each run of test reaction, the required ionic liquid version of Vilsmeier reagent was prepared by mixing the Trichloro-1,3,5-triazine (1b) $(0.183 \mathrm{~g}, 1.0$ mmol) and DMF-like ionic liquid (1a) $(1.272 \mathrm{~g}, 3 \mathrm{mmol})$ by stirring both at $25^{\circ} \mathrm{C}$ in $10 \mathrm{~mL}$ dichloromethane as co-solvent to reduce the viscosity. After preparation of Vilsmeier reagent, required mole ratio of the alcohol and carboxylic acid was introduced in the activated complex in acetonitrile. The resulting reaction mixture was stirred at required temperatures until the GC-MS showed the completion of reaction. After completion of reaction, the consumed cyanuric chloride was extracted with distilled water and product was extracted with diethyl ether. The organic layer was then concentrated and dried with $\mathrm{NaSO}_{4}$. After evaporation of the solvent the desire ester product was obtained in pure form as evident from TLC analysis. The products were characterized by ${ }^{1}$ HNMR. Spectral data for some representative compounds are available.

\subsection{Spectral Data of Synthesized Products}

\section{Ethyl acetate (1)}

${ }^{1} \mathrm{HNMR}\left(400 \mathrm{MHz}, \mathrm{CDCl}_{3}\right) \delta 4.05(\mathrm{q}, 2 \mathrm{H}, J=6.96 \mathrm{~Hz}), 1.96(\mathrm{~s}, 3 \mathrm{H}), 1.18(\mathrm{t}$, $3 \mathrm{H}, J=6.96 \mathrm{~Hz}) ;{ }^{13} \mathrm{CNMR}\left(300 \mathrm{MHz}, \mathrm{DCCl}_{3}\right): \delta 171.53,60.69,20.89,14.25$; HRMS (ESI): calcd for $\mathrm{C}_{4} \mathrm{H}_{8} \mathrm{O}_{2}\left(\mathrm{M}^{+}\right)$88.1051, found 88.1050.

\section{$n$-Butylacetate (2)}

${ }^{1} \mathrm{HNMR}\left(400 \mathrm{MHz}, \mathrm{CDCl}_{3}\right) \delta 4.09(\mathrm{q}, 2 \mathrm{H}, J=6.50 \mathrm{~Hz}), 2.10(\mathrm{~s}, 3 \mathrm{H}), 1.86(\mathrm{~m}$, $1 \mathrm{H}), 1.63(\mathrm{~m}, 2 \mathrm{H}, J=6.50, J=7 \mathrm{~Hz}), 0.87(\mathrm{~s}, 3 \mathrm{H}) ;{ }^{13} \mathrm{CNMR}\left(300 \mathrm{MHz}, \mathrm{DCCl}_{3}\right): \delta$ $171.68,62.17,37.50,22.33,22.67,20.93$; HRMS (ESI): calcd for $\mathrm{C}_{7} \mathrm{H}_{14} \mathrm{O}_{2}\left(\mathrm{M}^{+}\right)$ 130.1849 , found 130.1847 .

\section{n-Butyl benzoate (3)}


${ }^{1} \mathrm{HNMR}\left(400 \mathrm{MHz}, \mathrm{CDCl}_{3}\right) \delta 8-7.50(\mathrm{~m}, \mathrm{Ar}-\mathrm{H}), 4.24(\mathrm{t}, 2 \mathrm{H}, J=6.51), 1.75$ (dd, $2 \mathrm{H}, J=6.51, J=6.85$ ), 1.46 (t.d, $2 \mathrm{H}, J=6.85, J=6.71$ ), 0.95 (t, $3 \mathrm{H}, J=6.71$ ); ${ }^{13} \mathrm{CNMR}\left(300 \mathrm{MHz}, \mathrm{DCCl}_{3}\right.$ ): $\delta 171.74,151.32,129.26,125.68,121.41,34.40$, 27.80, 23.20, 14.00; HRMS (ESI): calcd for $\mathrm{C}_{11} \mathrm{H}_{14} \mathrm{O}_{2}\left(\mathrm{M}^{+}\right)$178.2277, found 178.2277.

Phenyl-3-phenylacrylate (4)

${ }^{1} \mathrm{HNMR}\left(400 \mathrm{MHz}, \mathrm{CDCl}_{3}\right) \delta 7.92-7.88(\mathrm{~m}, 1 \mathrm{H}, J=15.84), 7.57-7.41(\mathrm{~m}$, Ar-H), $7.41-7.16$ (m, Ar-H), $6.96-6.95(\mathrm{~m}, 1 \mathrm{H}, J=15.84) ;{ }^{13} \mathrm{CNMR}(300 \mathrm{MHz}$, $\left.\mathrm{DCCl}_{3}\right): \delta 163.96,150.18,144.81,135.44,129.65,128.49,127.92,126.29,121.67$, 115.58; HRMS (ESI): calcd for $\mathrm{C}_{15} \mathrm{H}_{12} \mathrm{O}_{2}\left(\mathrm{M}^{+}\right)$224.2546, found 224.2545 .

\section{Isopentyl benzoate (5)}

${ }^{1} \mathrm{HNMR}\left(400 \mathrm{MHz}, \mathrm{CDCl}_{3}\right) \delta 8-7.45(\mathrm{~m}, \mathrm{Ar}-\mathrm{H}), 4.29(\mathrm{t}, 2 \mathrm{H}, J=6.50), 1.69$ $(\mathrm{dt}, 2 \mathrm{H}, J=6.50, J=7.0), 1.60(\mathrm{~m}, 1 \mathrm{H}), 0.87(\mathrm{~d}, 3 \mathrm{H}, J=6.47) ;{ }^{13} \mathrm{CNMR}(300$ $\left.\mathrm{MHz}, \mathrm{DCCl}_{3}\right): \delta 172.29,151.00,129.36,125.68,120.86,32.40,31.58,28.46,22.16$; HRMS (ESI): calcd for $\mathrm{C}_{12} \mathrm{H}_{16} \mathrm{O}_{2}\left(\mathrm{M}^{+}\right)$192.2542, found 192.2540.

Cyclohexyl benzoate (6)

${ }^{1} \mathrm{HNMR}\left(400 \mathrm{MHz}, \mathrm{CDCl}_{3}\right) \delta 8.06-7.46(\mathrm{~m}, \mathrm{Ar}-\mathrm{H}), 4.90(\mathrm{~m}, 1 \mathrm{H}), 1.78-1.73$ $(\mathrm{m}, 2 \mathrm{H}), 1.28-1.21(\mathrm{~m}, 2 \mathrm{H}), 1.19-1.13(\mathrm{~m}, 2 \mathrm{H}) ;{ }^{13} \mathrm{CNMR}\left(300 \mathrm{MHz}, \mathrm{DCCl}_{3}\right): \delta$ $164.80,132.70,129.70,128.20,70.90,30.40,24.70,22.20$; HRMS (ESI): calcd for $\mathrm{C}_{13} \mathrm{H}_{16} \mathrm{O}_{2}\left(\mathrm{M}^{+}\right)$204.2649, found 204.2647.

tert-butyl benzoate (7)

${ }^{1} \mathrm{HNMR}\left(400 \mathrm{MHz}, \mathrm{CDCl}_{3}\right) \delta 8.20-7.61(\mathrm{~m}, \mathrm{Ar}-\mathrm{H}), 1.56(\mathrm{~s}, 9 \mathrm{H}) ;{ }^{13} \mathrm{CNMR}$ (300 MHz, $\mathrm{DCCl}_{3}$ ): $\delta 165.48,133.15,129.47,128.35,80.46,28.27$; HRMS (ESI): calcd for $\mathrm{C}_{11} \mathrm{H}_{14} \mathrm{O}_{2}\left(\mathrm{M}^{+}\right)$178.2277, found 178.2277.

Isobenzofuran-1,3-dione (8)

${ }^{1} \mathrm{HNMR}\left(400 \mathrm{MHz}, \mathrm{CDCl}_{3}\right) \delta 8.09(\mathrm{~m}, 2 \mathrm{H}), 7.98(\mathrm{~m}, 2 \mathrm{H}) ;{ }^{13} \mathrm{CNMR}(300 \mathrm{MHz}$, $\left.\mathrm{DCCl}_{3}\right): \delta 163.03,136.17,131.05,125.47$; HRMS (ESI): calcd for $\mathrm{C}_{8} \mathrm{H}_{4} \mathrm{O}_{2}\left(\mathrm{M}^{+}\right)$ 148.1156, found 148.1155 .

\section{Diethylmalonate (9)}

${ }^{1} \mathrm{HNMR}\left(400 \mathrm{MHz}, \mathrm{CDCl}_{3}\right) \delta 3.73(\mathrm{~s}, 6 \mathrm{H}), 3.33(\mathrm{~s}, 2 \mathrm{H}) ;{ }^{13} \mathrm{CNMR}(300 \mathrm{MHz}$, $\mathrm{DCCl}_{3}$ ): $\delta 167.12,51.69,40.48$; HRMS (ESI): calcd for $\mathrm{C}_{5} \mathrm{H}_{8} \mathrm{O}_{2}\left(\mathrm{M}^{+}\right)$132.1146, found 132.1144 .

\section{Dimethylhexandioate (10)}

${ }^{1} \mathrm{HNMR}\left(400 \mathrm{MHz}, \mathrm{CDCl}_{3}\right) \delta 3.51(\mathrm{~s}, 6 \mathrm{H}), 2.26(\mathrm{~m}, 4 \mathrm{H}), 1.64(\mathrm{~m}, 2 \mathrm{H}), 1.57$ (m, 2H), 1.49 (m, 2H); ${ }^{13} \mathrm{CNMR}\left(300 \mathrm{MHz}, \mathrm{DCCl}_{3}\right): \delta 175.05,51.40,33.75,24.00$; HRMS (ESI): calcd for $\mathrm{C}_{8} \mathrm{H}_{14} \mathrm{O}_{4}\left(\mathrm{M}^{+}\right)$174.1944, found 174.1940 .

\section{Dihydro-pyran-2,6-dione (11)}

${ }^{1} \mathrm{HNMR}\left(400 \mathrm{MHz}, \mathrm{CDCl}_{3}\right) \delta 2.51-2.48(\mathrm{~m}, \mathrm{e}-\mathrm{H}), 2.45-2.36$ (m, a-H), $2.47-2.37$ (m, a-H), 2.47-(m, e-H), $2.11-2.08$ (m, e-H), $1.93-1.90$ (m, a-H); ${ }^{13} \mathrm{CNMR}$ (300 $\left.\mathrm{MHz}, \mathrm{DCCl}_{3}\right): \delta 168.15,29.85,16.40$; HRMS (ESI): calcd for $\mathrm{C}_{4} \mathrm{H}_{8} \mathrm{O}_{2}\left(\mathrm{M}^{+}\right)$ 114.0993, found 114.0992.

Tetrahydropyran-2-one (12)

${ }^{1} \mathrm{HNMR}\left(400 \mathrm{MHz}, \mathrm{CDCl}_{3}\right) \delta 4.21-4.18(\mathrm{~m}, \mathrm{a}-\mathrm{H}), 4.24(\mathrm{~m}, \mathrm{e}-\mathrm{H}), 2.50-2.39$ 
(m, a-H), $2.54-2.50$ (m, e-H), $1.72-1.69(\mathrm{~m}, \mathrm{e}-\mathrm{H}), 1.79(\mathrm{~m}, \mathrm{e}-\mathrm{H}) ;{ }^{13} \mathrm{CNMR}(300$ $\mathrm{MHz}, \mathrm{DCCl}_{3}$ ): $\delta 171.20,69.31,29.79,22.36,19.00$; HRMS (ESI): calcd for $\mathrm{C}_{5} \mathrm{H}_{8} \mathrm{O}_{2}$ $\left(\mathrm{M}^{+}\right) 100.1158$, found 100.1157 .

\section{Results and Discussion}

The ionic liquid based Vilsmeier reagent (1c) has been obtained according to our reported procedure by treating the 3 moles of Dimethylformamide (DMF-like ionic liquid) (1a) with one mole of trichlorotriazine (1b) as shown in (Scheme 1) [12].

In the light of the reported applications of ionic liquid based Vilsmeier reagent studied so far [13] [14] [15] [16] [17], it seems justifiable to expect its capacity in promoting the esterification of various combinations of carboxylic acids and alcohols. As a test reaction, we started the esterification of benzoic acid and isoamyl alcohol catalysed by ionic liquid based Vilsmeier reagent.

Esterification reaction between an alcohol and a carboxylic acid occurs with intermolecular dehydration. The reaction procedure is developed according to the possible mechanistic path of the reaction as shown in (Scheme 2) and (Scheme 3). The logical question arises that which molecule would enter into the reaction with its hydroxy group and which one with its hydrogen atom. This depends on the mechanism of reaction which on the other hand depends on the sequence of addition of reactants. The choice that which molecule should use its hydroxy group may affect the rate and yield of the reaction. For example if we start the reaction by dissolving the IL-based Vilsmier reagent in dichloromethane then we have the choice either to add an alcohol or carboxylic acid. The both molecules are capable of reacting with the ionic liquid reagent (2a) using<smiles></smiles>

Scheme 1. Preparation of ionic liquid version of Vilsmeier reagent (1c).

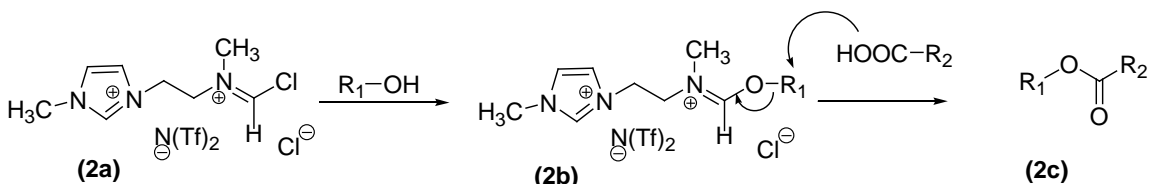

Scheme 2. Carboxylic acid as a nucleophile in IL-based Vilsmeier reagent promoted esterification.

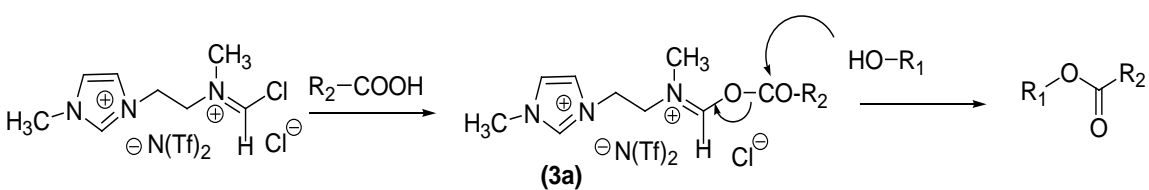

Scheme 3. Alcohol as a nucleophile in IL-based Vilsmeier reagent promoted esterification. 
their hydroxy group to give reactive complex (2b). However rate of the reaction of IL-reagent with alcohol will be relatively higher as compared to that of acid. Then carboxylic acid is added to react with the complex (2b) formed between an alcohol and IL-reagent to give ester (2c).

Another option is to treat the IL-based Vilsmeier reagent with carboxylic acid to form complex (3a) then add alcohol which will react with carbonyl carbon of the acid present in reactive intermediate $(3 \mathrm{c})$.

Second option seems to be more productive and efficient as compared to first one. With this theoretical prediction we proceeded as follows:

As a test reaction, we started the ionic liquid based chloroiminium reagent catalyzed esterification with benzoic acid and isoamyl alcohol. Keeping this idea in mind optimized condition were developed using equimolar amounts of benzoic acid and isoamyl alcohol. The IL-based Vilsmier reagent worked well to produce isopentyl benzoate in excellent yield of $98 \%$.

\subsection{Optimization of Reaction Conditions}

The ionic liquid based Vilsmeier reagent was prepared from DMF-like ionic liquid according to reported procedure. The ionic liquid based chloroiminium reagent $(1 \mathrm{mmol}, 0.476 \mathrm{mg}$ ) was dissolved in $3 \mathrm{~mL}$ of anhydrous methylene chloride $\left(\mathrm{CH}_{2} \mathrm{Cl}_{2}\right)$ at $10^{\circ} \mathrm{C}$. Then equimolar amount of benzoic acid $(1 \mathrm{mmol}, 0.122 \mathrm{mg})$ in form of solution in $\mathrm{CH}_{2} \mathrm{Cl}_{2}$ was added drop wise to ionic liquid solution with constant stirring to ensure homogenous mixing and smooth formation of reactive complex (3a). Reason for slow addition at lower temperature is to prevent the reaction of incoming acid as nucleophile on carbonyl of acid in complex to form anhydride. The progress of reaction was monitored by GC-MS analysis till the completion of the formation of reactive complex (3c). The first step was completed within 45 minutes. Then the complex was treated with 1 mole equivalent of isoamyl alcohol ( $1 \mathrm{mmol}, 0.080 \mathrm{mg}$ ) drop wise by dropping funnel and the mixture was stirred at $25^{\circ} \mathrm{C}$ and progress of the reaction was monitored by GC-MS analysis. The isoamyl benzoate ester was obtained within 15 minutes.

After completion of the reaction, the dichloromethane solvent was removed under vacuo and the product isoamyl benzoate was extracted with diethyl ether from regenerated DMF-like ionic liquid. The ionic liquid was washed with distilled water to remove water soluble ions. The recovered DMF-like ionic liquid was dried in oven at $80^{\circ} \mathrm{C}$ then in desiccator. The GC analysis indicated the $98 \%$ yield of isoamyl benzoate ester and no trace of any possible side product like anhydride or ether was observed. The product was further characterized by spectroscopic techniques.

\subsection{Scope of Developed Procedure}

The scope of current methodology was further examined using structural variety of both carboxylic acids and alcohols. Various types of aliphatic and aromatic alcohols were treated with different carboxylic acids which provided the corres- 
ponding esters from good to excellent yields. The results obtained are shown in Table 1. Every combination was selected with particular object to get insight into the structural compatibility of new protocol.

Using the optimized conditions, we initially tested the esterification between simpler substances like acetic acid and ethanol which provided the corresponding esters in quantitative yields (100\%). The esterification of acetic acid with

Table 1. Ionic liquid based chloroiminium reagent catalyzed esterification.

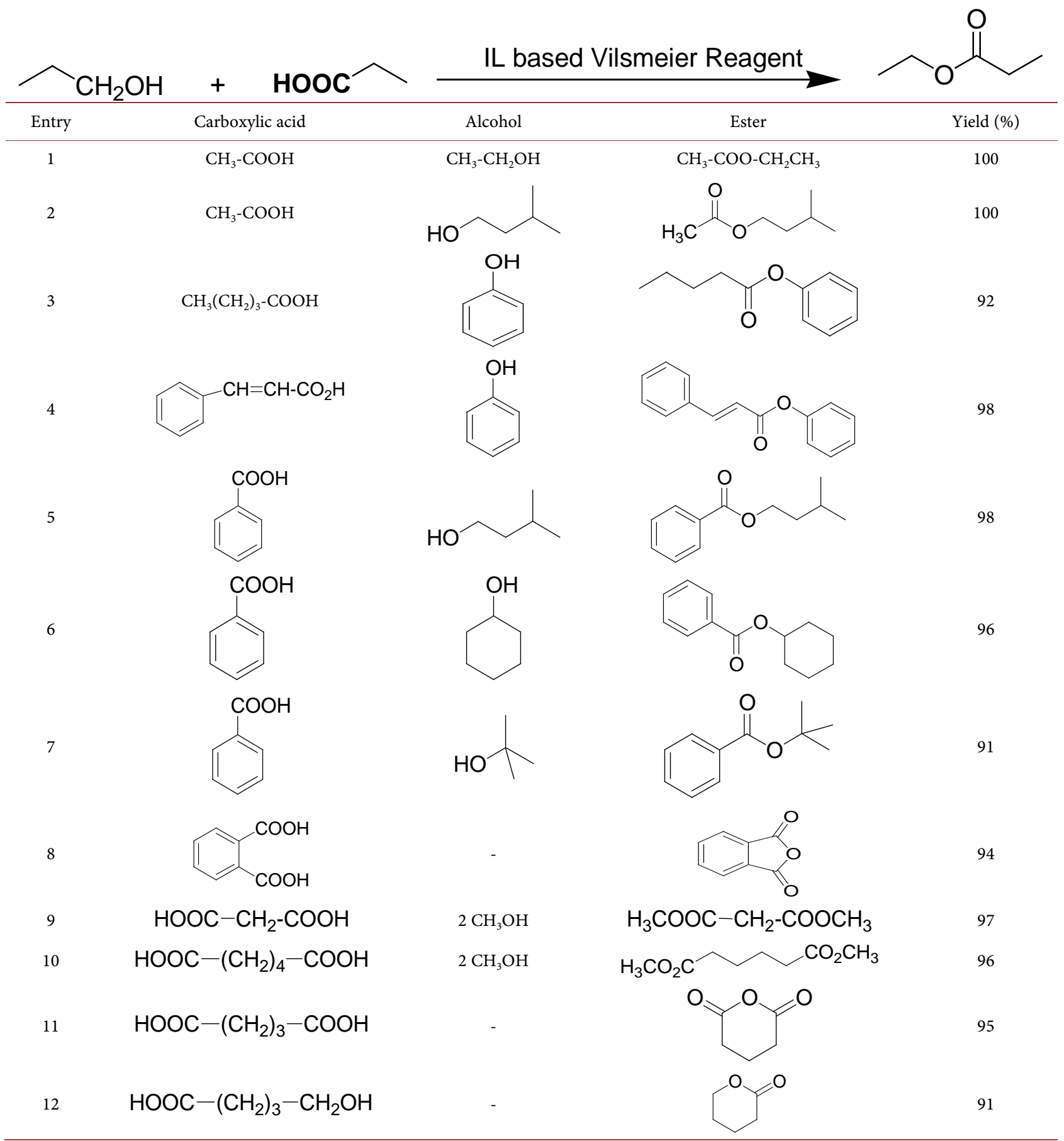

Yield (\%) (G.C analysis). 
isoamyl alcohol proved the power of current methodology by providing 100\% yield (Table 1, entry 1,2 ). In case of equimolar ratio of reagent and acid or alcohol no intramolecular dehydration was observed from both to give acid anhydride or ether respectively. The long chain carboxylic acid i.e. valeric acid on reaction with aromatic alcohol i.e. phenol provided corresponding ester in 92\% yield (Table 1, entry 3 ). The reduction in yield may be ascribed to the formation of side products. The best yield of phenyl cinnamate ester (98\%) was obtained from cinnamic acid and phenol. The benzoic acid on reaction with isoamyl alcohol (primary alcohol), cyclohexyl alcohol (secondary alcohol) and tertiary butyl alcohol gave corresponding esters in yields according to expected pattern i.e. the yield decreased with increasing steric hindrance around hydroxyl group.

Some dicarboxylic acids were also subjected to current procedure without adding alcohol i.e. phthalic acid and 1,5-pentandioic acid. They furnished corresponding anhydrides in best yields (Table 1, entry $8 \& 11$ ). Some dicarboxylic acids were also treated with required mole ratio of monohydroxy alcohols i.e. (Table 1, entry $9 \& 10$ ). They provided the diesters along with some traces of anhydrides. In our case it is manifested from the reduced yields of esters of (Table 1, entry 9, 10,). 5-Hydroxypentanoic acid on intramolecular esterification provided lactone in quantitative yield. The cyclic anhydride is favoured when the number of spacer atoms between two carboxyl groups is appropriate for intramolecular esterification reaction. The best yields of esterification reaction comes from the dicarboxylic acids which led to the formation of six- and five-membered cyclic anhydride. All the results obtained are summarized in (Table 1). Most of the reactions provided the best yields of esters under current procedure.

At the end of every reaction, we had ester product and in certain cases some by products, dichloromethane, traces of water and the regenerated DMF-like ionic liquid. The ionic liquid, $\mathrm{CH}_{2} \mathrm{Cl}_{2}$ and water formed immiscible layers thus easy to separate. The procedure was easily executable under green conditions. Entire operational profile indicates the success of developed procedure. We have checked the limited number of compounds and more detailed aspects can be further investigated.

\section{Conclusion}

The ionic liquid based Vilsmeier reagent has been shown to be an efficient organocatalyst for esterification of structurally divorce carboxylic acids and alcohols. The current method is green because it does not involved environmentally hazardous solvents. Due to lack of work-up cost and recycling of ionic liquid, it is not economically viable. The required esters were obtained in excellent yields in lesser time period as compared to other routine procedures. The most remarkable aspect of current method is easy recovery of products in pure state by simple extraction with ether without laborious work-up. The ionic liquid can be used recycled without loss of catalytic efficiency. This method is superior to other reported methods in terms of cost, labor and efficiency. 


\section{Acknowledgments}

The author gratefully acknowledge financial support by Higher Education Commission, Pakistan and HEJ international centre for biological and chemical sciences, university of Karachi, Pakistan for spectroscopic and GC-MS facilities.

\section{References}

[1] Hullio, A.A. and Mastoi, G.M. (2011) Designing Synthesis and Applications of Task Specific Ionic Liquids. Oriental Journal of Chemistry, 27, 1591-1612.

[2] Vilsmeier, A. and Haack, A. (1927) Über die Einwirkung von Halogenphosphor auf Alkyl-formanilide. Eineneue Methode zur Darstellung sekundärer und tertiärer p-Alkylamino-benzaldehyde. European Journal of Inorganic Chemistry, 60, 119-122. https://doi.org/10.1002/cber.19270600118

[3] Rajput, A.P. and Girase, P.D. (2012) Review Article on Vilsmeier-Haack Reaction. International Journal of Pharmaceutical, Chemical and Biological Sciences, 3, 25-43.

[4] Mokhtari, B., Roya, A. and Aseieh, A. (2010) 2,4,6-Trichloro-1,3,5-Triazine/Dimethylformamide as an Efficient Reagent for One-Pot Conversion of Alcohols into $N$-Alkylphthalimides. Chinese Chemical Letters, 21, 171-174. https://doi.org/10.1016/j.cclet.2009.10.006

[5] De Luca, L., Giacomelli, G. and Porcheddu, A. (2002) An Efficient Route to Alkyl Chlorides from Alcohols Using the Complex TCT/DMF. Organic Letters, 4, 553-555. https://doi.org/10.1021/ol017168p

[6] De Luca, L., Giacomelli, G. and Porcheddu, A. (2001) A Mild and Efficient Alternative to the Classical Swern Oxidation. The Journal of Organic Chemistry, 66, 7907-7909. https://doi.org/10.1021/jo015935s

[7] Akhlaghinia, B. and Elham, R. (2007) Efficient Method for Tetrahydropyranylation of Phenols and Alcohols Using 2,4,6-Trichloro[1,3,5]triazine. Turkish Journal of Chemistry, 31, 83-88.

[8] De Luca, L., Giacomelli, G. and Porcheddu, A. (2002) Beckmann Rearrangement of Oximes under Very Mild Conditions. The Journal of Organic Chemistry, 67, 6272-6274. https://doi.org/10.1021/jo025960d

[9] Hamona, F., Priéa, G., Lecornuéa, F. and Papot, P. (2009) Cyanuric Chloride: An Efficient Reagent for the Lossen Rearrangement. Tetrahedron Letters, 50, 6800-6802. https://doi.org/10.1016/j.tetlet.2009.09.115

[10] Neises, B. and Steglich, W. (1978) Simple Method for the Esterification of Carboxylic Acids. Angewandte Chemie International Edition in English, 17, 522-524. https://doi.org/10.1002/anie.197805221

[11] Savita, K., Ajay, K. and Gupta, A.K. (2002) A Simple and Convenient One-Pot Synthesis of Fatty Acid Esters from Hindered Alcohols Using $N, N$-DimethylchloroSulfitemethaniminium Chloride as Dehydrating Agent. Synthetic Communications, 32, 2885-2898. https://doi.org/10.1081/SCC-120006474

[12] Hullio, A.A. and Mastoi, G.M. (2012) Preparation of Ionic Liquid-Based Vilsmeier Reagent from Novel Multi-Purpose Dimethyl Formamide-Like Ionic Liquid and Its Application. Chinese Journal of Chemistry, 30, 1647-1657. https://doi.org/10.1002/cjoc.201280028

[13] Hullio, A.A. and Mastoi, G.M. (2011) First Multipurpose Task Specific Ionic Liquids: Designing and Synthesis of Novel Dimethyl Formamide-Like Ionic Liquid and Its Application as a Green Solvent Alternative to Dimethyl Formamide Dependent 
Reactions. Asian Journal of Chemistry, 23, 5411-5418.

[14] Hullio, A.A. and Mastoi, G.M. (2011) Application of Multipurpose Dimethyl Formamide-Like Task Specific Ionic Liquid as a Recyclable Reagent for Direct Iodination of Alcohols. Iranian Journal of Catalysis, 1, 79-86.

[15] Hullio, A.A. and Mastoi, G.M. (2012) Nicotine-Based Ionic Liquid as a Green and Recyclable Catalyst for Morita Baylis-Hillman Reaction. Jordan Journal of Chemistry, 7, 125-138.

[16] Hullio, A.A. and Mastoi, G.M. (2012) Nicotine-Based Ionic Liquid: As a Green Catalyst for Pyridine-Catalyzed Huisgen Reaction. Iranian Journal of Catalysis, 2, 165-171.

[17] Hullio, A.A. and Mastoi, G.M. (2013) Ionic Liquid Based Vilsmier Reagent as a Substitute for Mitsunobu Reagent: Direct Conversion of Alcohols into Different Compounds under Ionic Liquid Conditions. International Journal of Chemistry, 5, 69-75. https://doi.org/10.5539/ijc.v5n3p57 